\title{
Discurso Utópico e Ação Política: Uma Reflexão Acerca da Politéia Platônica
}

\author{
Maria das Graças de Moraes Augusto \\ Universidado Federal do Rio de Janeiro \\ «... arkhè gàr kaî thè̀s en anthrópois \\ edryméne sóizei pánta» 1
}

PLATÃO, Leis, 775 e

A quoi sert l'utopie? A faire du sens. ROLAND BARTHES

\begin{abstract}
AUGUSTO, M. G. M. Discurso utópico e ação política: uma reflexão acerca da politéia platônica. Classica, Belo Horizonte, 3:37-59, 1990 .
\end{abstract}

ABSTRACT: Ancient greeks were not the creators of the word utopia but used extensively the utopic genre and mode to express their ideas on social organization. From Hippodamus of Miletus and Phaleas of Chalcedon, possibly inspired by Pythagoras and the first pythagoreans, to the sophists and Aristophanes, the theme slowly acquired philosophical content reaching its maturity with the platonic text. Plato's reflections on the relations between Philosophy and Politics, as presented in Letter VII, show that the Republic, while being a utopic construction, constitutes neither an ideal state (in the sense of being impossible to achieve and in oposition to real states) nor a historical imitation of political models (specially Sparta) but a possible course of political action.

O termo Utopia tem sua origem em 1516, quando Thomas Morus, descrevendo uma ilha imaginária, atribui-lhe o nome de "De optimo reipublicae statu de que nova insula Utopia". Etimolo-

1

... «o começo é um deus que, estabelecendo-se entre os homens, tudo salva.» CLASSICA, Belo Horizonte, $3: 45-66,1990$ 
gicamente o termo significa "não-lugar", "nenhum lugar", e é fruto da junção de duas palavras da língua grega, o advérbio de negação ou e o substantivo masculino tópos.

Dentre as diferentes acepções que o termo tópos assume no grego antigo, três são extremamente importantes para a construção do sentido e do uso da palavra utopia em sua historicidade. A primeira destas acepções refere-se à noção de lugar que se ocupa num determinado espaço. Espaço este que pode ser um terreno onde se constrói uma casa, um edifício, onde se faz um jardim, ou ainda, espaço no qual se situa um país, uma região, um território. Neste sentipo, tópos envolve não só uma obra, mas também o lugar, a posição que ela ocupa, a ocasião e a oportunidade, o kairós de se fazer uma coisa, passando, assim, de um sentido geográfico para um sentido metafísico. ${ }^{2}$

Em um segundo sentido, tópos aparece como um termo pertinente à retórica e à dialética, podendo remeter-nos não apenas aos principais pontos de uma demonstração, mas ao fundamento de um raciocínio e ao objeto ou matéria de um discurso. Aristóteles, na Retórica, usa o termo tópos para falar das partes essenciais da retórica e de um koinòs tópos, de um lugar comum, de tópicos que são comuns a todos. ${ }^{3}$

$\mathrm{E}$, finalmente, numa terceira acepção, a linguagem médica usa o termo tópos para referir-se ao lugar de um mal, à parte doente de um corpo. ${ }^{4}$

Assim, quando o pensamento renascentista busca um nome capaz de expressar inquietações políticas e metafísicas que emergem com a descoberta do Novo Mundo e a redescoberta do Mundo Antigo, inventa um termo que, questionando e de certo modo negando uma

\footnotetext{
Cf. Liddel \& Scott $1983: 1806$; Bailly 1984:1947; Chantraine 1968:1121; Boisacq $1950: 975-976$.

3 «Chamo espécies as premissas próprias de cada gênero, tópicos as que são comuns a todos». Retórica, 1358 a.

4

Cf. Hipócrates, Aforismos, II, 46: «Dyo tónon háma ginoménon me katà tòn auton tópon, ho sphodróteros hármauroi tòn héteron».
} 
prática política, recupera para a reflexão filosófica o "resíduo da teoria política antiga". 5

Deste modo, é neste "resíduo", significando permanência e retomada, que poderemos não só falar de "utopia" no pensamento antigo (recorrendo, pois, a um termo moderno), mas também estabelecer as diferenças essenciais entre as "utopias" do mundo clássico e as utopias renascentistas e modernas, pois, embora os gregos antigos não tenham sido os inventores do termo utopia, utilizaram largamente o gênero e modo utópicos. ${ }^{6}$

\section{Sobre a arkhé do discurso utópico}

Desde Homero e Hesíodo, encontramos na Literatura Grega descrições de "lugares ideais", isto é, lugares que não se manifestam na concretude da história, mas que, apresentados como alteridade, ultrapassam a própria história para permanecerem como fonte de reflexão.

O termo «resíduo», expressando aquilo que permanece, é utilizado por Joly (1986) ao analisar a questão da utopia no pensamento platônico. Assumindo uma posição intermediária entre aqueles que negam a legitimidade da utilização do termo «utopia» entre os gregos - como, por exemplo, Goldschmidt (1970) e aqueles que vêem nos gregos, sobretudo em Platão, a elaboração de um pensar utópico - como fazem, por exemplo, Vidal-Naquet e Levêque (1964), Joly (1985:326) procura definir a utopia como «... le résidu de la théorie politique ancienne, lorsque la lecture laisse échapper l'histoire des institutions et la philosophie des constitutions». Num âmbito distinto das posições acima mencionadas, Hansot (1974) tentará estabelecer diferenças entre as «utopias clássicas» e as «utopias modernas», a partir da dependência relativamente a uma forma particular de organização social: «Among the characteristics that disthinguish classical from modern utopian ideals, a most important feature of the classical utopian ideal is that its existence does not directly depend on a particular form of social organization but hinges rather upon the existence of a suprasssensible reality. (...) ... While modern utopian activity depends on a certain set of social arrangements》. (Hansot $1974: 2-3$ ) .

6

As grandes discussões acerca da possibilidade de se definir a utopia e de, consequientemente, superar suas ambigüidades têm suscitado algumas soluções que - mesmo não atingindo o objetivo último de estabelecer o escopo em que esta se insere - fundamentam e justificam a constituição de um gênero e de um modo utópicos. Como alguns autores sugerem, o gênero utópico deve ser pensado a partir de suas relações com outros gêneros literários, buscando aquilo que os aproxima e aquilo em que se diferenciam, para então descrevê-lo, como faz Trouson (1979:25), ao afirmar que, «... la description de l'utopie comme genre permet d'échapper à sa confiscation par les idéologies. Peu importe ici qu'elle soit anticipatrice ou passéiste, libératrice ou aliénante, 
progressiste ou reáctionnaire. Quelle que soit son orientation, elle fonctionne selon les mêmes principes, elle se décrit selon les mêmes critères, elle se compose des mêmes eléments. Que l'étude de l'utopisme, c'est-à-dire d'une certaine mentalité spéculative, soit en elle-même nécessaire et passionante, ce n'est pas douteux. Mais l'utopisme ne se confond pas plus étroitement avec l'utopie, que le tragique avec la tragédie, le comique avec la comédie, le romanesque avec le roman: il englobe certes le genre, mais aussi le dépasse. Cette distinction permettra peu-être d'éviter des confusions entre une attitude mentale ou idéologique et ce qui doit être tenu, en définitive, pour un raneau du genre romanesque, en tout cas pour un fait littéraire dont on peut tracer l'histoire.》 Assim, Ruyer (1950), aproxima e diferencia o gênero utópico do romance - sobretudo do romance científico - do conto fantástico, do mito. No que diz respeito ao romance e ao conto fantástico, o que permite, ainda segundo Ruyer, diferenciá-los da utopia é que esta se constitui como um jogo, portanto, o lúdico é dado essencial ao gênero utópico. Quanto ao mito, embora esteja bastante próximo da utopia, diferencia-se dela no que diz respeito ao elemento teorético: enquanto o mito quase sempre pretende explicitar a origem de um fenômeno ou mesmo a origem de todas as coisas, o elemento teorético manifesta-se na utopia como invenção e, ao inventar, ela é simultaneamente especulativa e prática: «Un mythe résume une donnée humaine éternelle sous la forme historique d'un récit. C'est la dramatisation d'une 'aporie'. En ce sens, il est inverse de l'utopie, qui arrive à l'eternel par l'histoire» (Ruyer 1950:5). Trousson (1979), por sua vez, ao tentar descrever - gênero utópico, levanta alguns itens que considera essenciais para a caracterização da utopia: seu aspecto primordialmente «insular»; o desprezo pelo ouro e, conseqüentemente, a escolha de um modelo econômico fechado e autárquico; o culto de um sistema exclusivamente agrícola; um funcionamento interno impecável e absolutamente regular; e, finalmente, um coletivismo capaz de definir a felicidade como sendo coletiva. Por outro lado, a exigência de compreensão do modo utópico faz com que alguns autores reconheçam aí a questão essencial do pensar utópico. Davis (1981:4-5), ao tentar estabelecer uma definição de utopia, privilegiará o modo utópico em detrimento de uma certa «tradição de pensamento»: «Utopia does not offer carte blanche to the political imagination, for, in choosing it, the writer is rejecting other possible forms of ideal society. Utopian writing is not a tradition of thought, although it thas usually been treated as one - with disastrous results. Rather, it is a mode or type of ideal society, and what utopian writers have in common is not common membership of a tradition but their subjection to a common mode. This explains the similarities to be found in the utopian works of writers of diverse traditions.(...) As a mode of visualing an ideal society utopia has remained relatively constant». Ruyer (1950:9), por sua vez, admite que é preciso descrever o modo utópico e, a partir dessa descrição, atingir a «essência» da utopia, o que lhe permite definir o modo utópico como um «exercise mental sur les possibles latéraux». O modo utópico, embora ligue-se ao campo do pensar, à ordem da teoria e da especulação, supõe, também, simultaneamente, um vínculo estreito com a ação, pois ele depende de uma primeira compreensão do real. Deste modo, suas relações são estreitas não só com a metafísica, a geometria, mas, sobretudo, com o «jogo» (o lúdico) e a invenção. Manuel \& Manuel (1980:4-5), em seu elaborado trabalho sobre o pensamento utópico no mundo ocidental, sublinham o fato de que «The descriptive and the discursive rhetorical modes in utopia are never, or rarely ever, found in a simon-pure state, since the living portrait of a utopia rests on a set of implicit psychological, philosophical, or theological assumptions about the nature of man, and the discursive exposition of utopian principles frequently has recourse to illustrations from ordinary events, proposes hyphothetical situations, and analogizes from other realms of being». 
Assim, os temas utópicos ${ }^{7}$ estão presentes nos dois grandes poemas épicos de Homero. Ferguson, em seu trabalho sobre as utopias no mundo antigo, ${ }^{8}$ mostra-nos que temos na Odisséia a primeira narrativa de um tópos utópico, quando o Olimpo é assim descrito:

Dito isto, Atena de olhos brilhantes afastou-se para o Olimpo, onde, dizem, é o assento perpetuamente seguro dos deuses. Não é sacudido pelos ventos ou molhado pelas chuvas, nem ali cai neve; mas cobre-o um céu puro, sem nuvens e duma esplendente claridade. Para aqui, onde os deuses bem-aventurados vivem em contínuo gozo, é que a deusa dos olhos brilhantes se afastou. ${ }^{9}$

Do mesmo modo, ao descrever a terra dos Feaces e a ilha dos Ciclopes, Homero nos dá o modelo temático dos "lugares ideais" que perpassarão a história do pensamento ocidental, construídos a partir de um ideário político. No palácio de Alcínoo,

crescem grandes e viçosas: pereiras, romãzeiras, macieiras de belo fruto, figueiras encantadoras e verdejantes oliveiras. Nestas árvores a fruta nunca se estraga nem falta, tanto no inverno como no verão; dura o ano todo, porque Zéfiro,

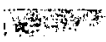
soprando contínuo, faz crescer uma e amadurar a outra. ${ }^{10}$

E na ilha dos Ciclopes,

homens soberbos e sem lei, que confiando nos deuses imortais, não plantam nem lavram, mas tudo lhes nasce espontaneamente, sem ser preciso semear nem lavrar - e a

7

Chamamos aqui de «temas utópicos» a temas como o da idade do ouro, da Arcádia, da Cucanha, das Ilhas dos Bem-Aventurados, etc..., que são controversos em relação ao seu status utópico, isto é, alguns autores vêem neles não só uma manifestação do gênero mas, também, do modo utópico, caracterizando-os, portanto, como utopias. Outros tratam-nos como temas afins da utopia, sem todavia reconhecerem neles um status utópico, uma vez que a utopia se vincula especificamente às construções de cidades imaginárias. Para uma primeira abordagem veja-se a obra de Ferguson (1975) e Trousson (1979). 8

Ferguson 1975 : 9-15.

9

Homero, Odisséia, VI, 43. (Tradução de E. Dias Palmeira).

10

Homero. Odisséia, VII, 112. Alguns autores vêem aqui a primeira đescrição utópica da literatura européia. Cf. Ferguson 1975 : 14. 
chuva de Zeus faz-lhes crescer todos os frutos. Não têm ágoras, onde deliberem, nem leis, mas vivem em grutas côncavas, no cimo dos altos montes; e cada um impera sobre os filhos e as mulheres sem cuidar um do outro. ${ }^{11}$

Nessas descrições, dois temas são fundamentais para a constituição do pensamento utópico: a idealização da natureza e a vida justa. ${ }^{12}$ Eles ressurgirão no século VII a. C. na obra de Hesiodo, expressando um conflito político mais acirrado do que o que Homero havia descrito - onde o justo e o injusto se confrontam. No poema Trabalhos e Dias, Hesíodo nos narra sua disputa jurídica com o irmão Perses e a forma pela qual os juízes, "comedores de presentes", se deixam corromper colocando a verdade e a justiça em segundo lugar.

Ora, é em ftınção de um fato concreto que Hesíodo nos colocará diante de uma discussão abstrata, onde as relações entre a dîke e a hybris são pensadas em função da existência da dor e do sofrimento na vida dos homens. Circunscrita a urna esfera onde os termos érgon, éris, e génos desempenham um papel fundamental, a díke, nos Trabalhos e Dias, assume a importância de um "tópico" que deve ser discutido. Opondo-a a kybris, Hesíodo personificará a dike como a virgem filha de Zeus. ${ }^{13}$

Vista dessa forma, a díke é poder e, enquanto poder, ela é também punição. Mas, aqui, é preciso esclarecer que a punição é uma dádiva ${ }^{14}$ de Zeus, que faz da díke um símbolo especificamente humano, na medida em que ela não só se opõe ao comportamento dos animais, mas é também identificada com um procedimento

\footnotetext{
11

Homero. Odisséia, IX, 106.

12

Ferguson (1975) chama a atenção para o fato de que teríamos nas duas descrições acima mencionadas, de um lado, uma Eutopia e, de outro, uma Cacotopia, e que, na descrição da ilha dos Ciclopes, Homero já teria esboçado a teoria aristotélica de que o homem é um animal político, através da oposição entre os selvagens (os ciclopes), que não possuem uma agorá, e os civilizados, que possuem uma vida política.

Hesiodo. Trabalhos e Dias, v. 220-223 e 256-263.

14

Hesíodo. Trabalhos e Dias, v. 274-285.
}

CLASSICA, Belo Horizonte, $3: 45.66,1990$ 
legal que é a condição necessária da existência de uma comunidade humana. ${ }^{15} \overline{\mathrm{E}}$ pois na tentativa de explicitar uma certa condição humana a partir da constatação da existência de duas Eris $^{15}$ (e não de uma, como havia dito na Teogonia), de naturezas diferentes - uma má, que instaura o sofrimento e a desordem entre os homens; e a outra boa, que Zeus introduziu na Terra, fazendo com que ela se manifeste como uma força vital que atua sobre os homens ${ }^{17}$ - que Hesíodo recorrerá ao mito das cinco idades.

Assim, o mito das cinco idades 18 insere-se no seio da contenda entre a hybris e a exigência da díke de uma nova ordem política emergente, ao narrar a história de uma primeira raça aurífera de homens mortais, criada pelos imortais do Olimpo, que, existindo no tempo em que Cronos reinava, não sofria nem desassossego, nem fadiga e vivia longe de qualquer miséria. Os frutos brotavam espontaneamente nas árvores e, livres de dores e doenças, os homens desta raça morriam ao dormir quando chegavam ao fim da velhice.

15

Havelock (1978:193-217), em seu estudo sobre o conceito de justiça na cultura grega antiga, mostra que Hesíodo, ao caracterizar a díke, está ainda vinculado à língua homérica. A presença da narrativa homérica da Terra dos Feaces nos Trabalhos e Dias é fundamental para a construção da idéia do justo como o «habitante da utopia»; a descrição da Idade do Ouro é uma «visão da homérica Terra dos Feaces». Por outro lado, a justiça em Hesíodo está longe de ser um conceito, e o sentido de punição que surge nos Trabalhos $e$ Dias só será cristalizado no momento em que a «legalidade» tornar-se literária. Sobre esta questão ver também Nestle (1973 : 43-50); Lesky (1985 : 114142); e Verdenius (1960:109-170).

16

Na Teogonia, Hesiodo havia chamado Eris à deusa da disputa, dentre os filhos da Noite: «Pariu ainda Nêmesis ruína dos mortais / a Noite funérea. Depois pariu Engano e Amor / e Velhice funesta e pariu Eris de animo cruel. / Eris hedionda pariu Fadiga cheia de dor, / Olvido, Fome e Dores cheias de lágrimas, / Batalhas, Combates, Massacres e Homicídios, / Litígios, Mentiras, Falas e Disputas, / Desordem e Derrota convenientes uma da outra, / e Juramento, que aos sobreterrâneos homens / muito arruína quando alguém adrede perjura.»Teogonia, v. 220-230. (Trad. de Torrano, 1981) . 17

Ver a interpretação de Lesky (1988:114-42), que encontra aqui um tema da excelência grega. Por outro lado, esta eficácia se manifesta no nível do trabalho e da ordem, categorias que ressurgem ao longo do pensamento utópico. 18

O mito das cinco idades reaparecerá de diferentes formas no pensamento grego, e Platão, no texto da Repuiblica, também não estará imune à influência de Hesíodo. Sobre este aspecto, veja-se a interessante análise que Frank e Fritzie Manuel (1979:64-92) fazem em seu estudo sobre o pensamento utópico; e Solmsen $(1970: 171-210)$. 
Depois que a terra sepultou esta raça, Zeus transformou-os em daimones. ${ }^{19}$

Em seu lugar, os deuses olímpicos criaram uma segunda estirpe de homens mortais feita de prata. Sendo esta inferior à anterior, não podiam ser comparados com os homens da idade de ouro, nem mesmo em seu aspecto físico. Estes tinham uma longa infância e, quando chegavam à juventude, não conseguindo afastar dentre eles as grandes violências, viviam pouco tempo e cheios de sofrimentos. Como não queriam prestar culto aos imortais, Zeus, irritado, aniquilou-os .

Após esta estirpe, Zeus criou uma terceira raça, de bronze, em nada semelhante à de prata, que se interessava apenas pelas obras de Ares e pelos atos de soberba; não comiam pão, tinham um coração de metal e, apesar de sua força, apoderou-se deles a morte.

Uma vez sepultada esta raça, Zeus colocou sobre a Terra uma raça mais justa e virtuosa, a raça dos heróis que lutaram em Tróia. A estes heróis, após a morte, Zeus concedeu vida e residência longe dos homens è longe dos sofrimentos, nas Ilhas dos BemAventurados.

A seguir, uma quinta geração, feita de ferro, passou a existir e é nesta que vive Hesíodo - quando os homens não estão livres de misérias e fadigas e os deuses lhes proporcionam grandes inquietações, embora mesclem, aos desassossegados, alegrias.

$\overline{\mathrm{E}}$ pois em meio a estas inquietações, que nos narra Hesíodo nos Trabalhos e Dias, que encontramos alguns paradigmas do pensamento utópico. De um lado, a relação entre o trabalho e o progresso: Hesíodo quer persuadir a Perses, seu irmão, de que a boa Eris se dá no trabalho honroso e é só pelo "progresso" 20 que a idade de ouro poderá ser recuperada. De outro, a disputa entre

19

Hesíodo parece ser o primeiro a usar o termo daimon para referir-se a divindades menores.

20

A polêmica questão sobre a existência ou não da noção de progresso entre os antigos foi discutida no texto, hoje clássico, do Professor Dodds (1973). Para uma história da noção de progresso ver o texto de Nisbet (1980). 
o justo e o injusto, refletindo uma crise ao nível da pólis, ${ }^{21}$ faz com que o modelo ideal de uma cidade justa passe a ser o princípio de exigência política frente à cidade injusta. Começamos, então, a sair do tema estrito de uma construção poética, para instalá-lo no centro da ágora, como fonte de discussões e reflexões. O espaço utópico começa então a se constituir como reflexão sobre a pólis.

Nesta reflexão é preciso pensar a cidade como uma categoria que se historializa, na medida em que, preconcebida, ela procura resolver ao nível teórico os problemas emergentes da crise política. Ainda quanto a isso, se considerarmos o testemunho de Aristóteles, os gregos deram contribuições para a elaboração de um pensamento utópico.

No livro II da Política, após ter feito a crítica dos modelos propostos por Platão na República e nas Leis, ${ }^{22}$ Aristóteles diz que existem vários outros projetos de Constituição, e que muitas delas emanam de filósofos e de homens versados na Política ${ }^{23}$ passando então a examinar os projetos propostos por Faleas de Calcedônia e Hipodamos de Mileto.

Faleas foi o primeiro a introduzir um plano de reformas e a declarar que as propriedades dos cidadãos deveriam ser iguais. Para que isto se tornasse exequiível, seria necessário que o Estado regulasse os casamentos, de modo que os ricos dessem dotes, sem, entretanto, receberem, enquanto os pobres ficariam livres de dá-los $;^{24}$ por outro lado, os artesãos deveriam ser todos escravos públicos, não fazendo parte do corpo dos cidadãos.

O segundo, Hipodamos, filho de Euryphon e natural de Mileto, é famoso por ter sido o inventor de divisão das cidades em quarteirões e por ter ordenado o Pireu em ruas. ${ }^{25} \mathrm{~A}$ cidade planejada

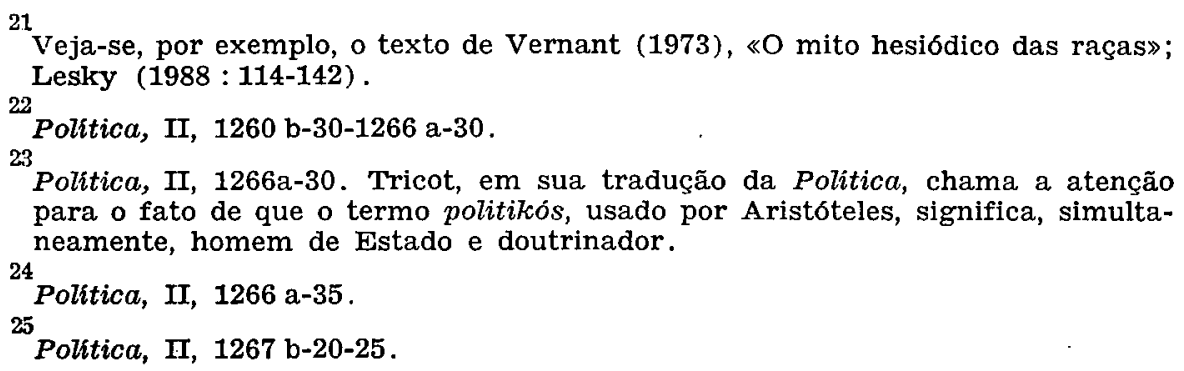


por Hipodamos deveria ter uma população de dez mil habitantes, divididos em três classes: artesãos, agricultores e guerreiros, que, por sua vez, habitariam um território também dividido em três partes. A primeira parte, sagrada, seria destinada às oferendas tradicionalmente feitas aos deuses; a segunda, pública, serviria para o uso dos guerreiros; e a terceira parte, privada, estaria reservada para o uso dos agricultores. Por outro lado, existiriam também três formas de leis, uma vez que os fatos que exigem a ação da justiça são três: o ultraje, o dano e o homicídio; ${ }^{26}$ os magistrados seriam eleitos pelo povo, constituído pelas três classes.

De tudo que diz Aristóteles sobre a Constituição proposta por Hipodamos, há ainda algo extremamente importante: ele é o primeiro que, estrangeiro às questões de estado, se propõe a traçar o plano de uma Constituição Ideal. ${ }^{27}$

A partir daí, o pensamento utópico começa a se constituir como o ato de inventar cidades, de modo independente da formação da pólis - e aqui é interessante observar que a Filosofia esteve sempre ligada a esta atividade. Desde Tales ${ }^{28}$ até Protágoras, o tema vai lentamente adquirindo um conteúdo filosófico, e as críticas dos poetas cômicos, sobretudo as de Aristófanes, ${ }^{29}$ são fontes

\footnotetext{
26

Politica, II, 1267 b-30-35.

$27^{-}$

Política, Ir, 1267 b-25. Strauss (1978:17), ao analisar a Política de Aristóteles, vê em Hipodamos de Mileto o primeiro filósofo político: «The first political philosopher will then be the first man not engaged in political life who attempted to speak about the best political order. That man, Aristotles tells us, was a certain Hippodamus». 28

As relações entre a Filosofia e a invenção de cidades parecem estar, descle os primórdios da Filosofia, interligadas: «Faut-il voir dans ce projet [a constituição de Tales de Mileto] la première utopie de la philosophie? (VidalNaquet \& Lévêque $1964: 143$ ). 29

Desde os primórdios da comédia antiga vemos as críticas dos poetas aos inventores de cidades. A primeira «utopia» da comédia parece ser o texto de Cratinus, Plon̂toi (Cf. Barkeh $1977: 92$ ). Aristófanes, em As Aves, descrevendo Cucopólis, nos fala de Méton, o urbanista, que, com um esquadro, um compasso e urn cordão, quer «medir o ar e dividi-lo em porções», e a quem Pistetero, assombrado, compara com Tales («Este homem é um Tales») .
} 
importantíssimas para a compreensão da apropriação filosófica desta atividade, definida por Aristóteles como a "tentativa de projetar a melhor politéia". ${ }^{30}$

Ora, definida desta forma, é no texto platônico que encontraremos o momento de maturidade do tema da utopia, pois é aí, na obra de Platão, que a Filosofia e a Política, enquanto reflexão sobre o homem, a sua natureza e a sua condição, lançam mão da invenção de cidades "ideais", como um recurso onde a Filosofia política se torna possível.

E nesta encruzilhada da reflexão filosófica e política que pretendemos analisar a politéia proposta por Platão.

\section{Sobre a política e a utopia na República}

As interpretações do pensamento politico de Platão, que associam a justa cidade utópica construída na Repriblica a uma forma totalitária de pensar a política ou a uma forma alienante de escapar a ela, quase sempre ilustram suas teses com o fracasso dos acontecimentos políticos em Siracusa. ${ }^{31}$

Uma leitura atenta da Carta VII ${ }^{32}$ — onde Platão conta não só os eventos da Sicília, mas traça a gênese de todo o seu interesse

\footnotetext{
30

Aristóteles, Política, II, 1267 b-25: «...prôtos tôn mè politeoménon enekheíresé ti perì politeias eipeîn tês aristês». 31

Ver, por exemplo, de Popper (1959:33-50) o cap. 9 e o cap. 10, onde discute a questão da tirania a partir das informações da Carta VII e conclui, equivocadamente, a nosso ver, que Platão «com toda a sua intransigente limpeza de tela, foi levado por um caminho em que comprometeu sua integridade. (...) Apesar de seu próprio ódio à tirania, foi levado a procurar ajuda num tirano e a defender as mais tirânicas medidas» (1987:218-19); Arendt, Martin Heidegeer faz oitenta anos (p. 229-231); Grene (1967:164-76); e Sinclair (1967 : 143-168).

32

Apesar das extremadas controvérsias acerca da autenticidade da Carta VII, muitos estudiosos contemporâneos tendem ao reconhecimento da mesma. A favor da autenticidade, ver Haward (1928); Bluck (1947); Pasquali (1938); contrários à autenticidade, veja-se Edelstein (1966); Gulley (1972) .
} 
pela política ${ }^{33}$ - permite-nos constatar que sua reflexão sobre a politica tem origem, paradoxalmente, no momento em que reconhece a impossibilidade de concretizar seus projetos de intervir na vida política ateniense. De acordo com seu relato, suas "desilusões" com a política foram marcadas por dois acontecimentos cruciais para sua reflexão: a tirania dos trinta e a morte de Sócrates. ${ }^{34}$

O primeiro suscitou-lhe as esperanças de uma "nova ordem" que governasse através dos caminhos da justiça, mas o que ocorreu foi que os trinta governaram através da mais feroz injustiça, tentando comprometer, em suas ações criminosas, o próprio Sócrates, o mais justo e o mais sábio dos atenienses, ${ }^{35}$ que, por não obedecê-los, expôs-se aos maiores perigos.

Quando os Trinta caíram e a Democracia foi restaurada, antes que novas esperanças pudesem ser articuladas, a condenação de Sócrates, por esta Democracia que ele ajudara a restabelecer, fez com que Platão passasse a desconfiar da política de seu tempo e, embora tivesse "esperado sempre o bom momento para agir", 36 acabou por constatar que "todas as cidades atuais possuem um má politéia, pois suas leis se encontram num estado praticamente incurável, uma vez que não foram objeto de um cuidado extraordinário em circunstâncias favoráveis (thaumastês tinos metà tykhes) . ${ }^{37}$ Tais reflexões o levam não só a elogiar a reta filosofia (epainôn tèn orthèn philosophían) e a proclamar que somente à sua luz se pode reconhecer onde está a justiça na vida pública

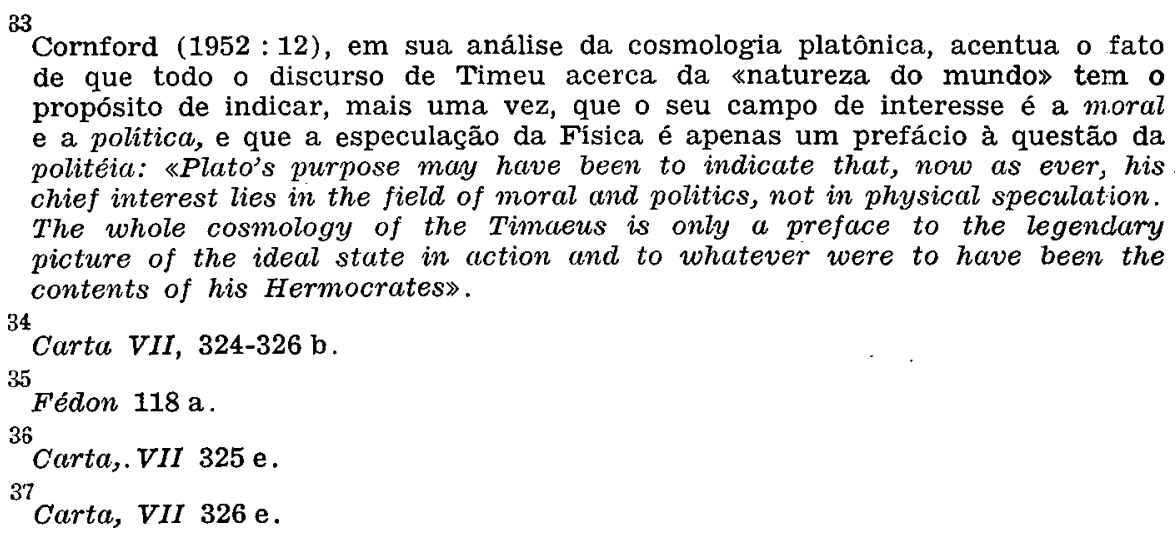


e na vida privada, 38 mas a concluir que os males não acabarão para os humanos antes que a raça dos puros e autênticos filósofos chegue ao poder ou antes que aqueles que têm o poder nas cidades, "por uma especial graça da divindade (moíras théas), se ponham verdadeiramente a filosofar". 39

Estes dois acontecimentos têm um papel fundamental no pensamento político de Platão, pois comprometem decisivamente a Filosofia e a Politica.

$\mathrm{O}$ acontecimento político da Tirania exige que o filósofo pense sua tarefa pela ótica do poder, discordando radicalmente, porém, do poder absoluto do tirano, que é fonte de injustiça e de ignorância.

A reta filosofia, por sua vez, é, aos olhos de Platão, o único discurso capaz de desmaterializar o poder político de sua aura compulsiva e, colocando-o num outro tópos, faz com que o acontecimento político da morte de Sócrates o determine. Ou seja, a morte de Sócrates - o primeiro filósofo ateniense e que quase sempre se abstivera de tomar parte na vida política — aponta para uma esfera em que o ideal socrático de virtude se manifesta na reflexão platônica como a forma "justa" da política.

Todavia, este ideal não poderia realizar-se em nenhum Estado histórico, pois ele supunha não só uma ação política centrada na dikaiosyne, mas que o poder político, unindo-se à filosofia, se manifestasse como um princípio - a idéia de Bem - que, estando acima de governantes e governados, faz com que ele se transforme em lógos e a seguir em sophía.

O cidadão é aí definido não como aquele que participa do poder político, mas como aquele que participa deste princípio que, transcendendo a própria comunidade, compromete o pensamento político da filosofia.

Assim, o que inicialmente depreendemos da leitura da Carta VII é que seus destinatários não são apenas os amigos e parentes de Díon, mas todos aqueles que, como Trasímaco, Gláucon e Adimanto,

\footnotetext{
38

Carta VII, 326 a.

39

Carta VII, $326 \mathrm{~b}$.
}

CLASSICA, Belo Horizonte, $3: 45.66,1990$ 
pensam a política apenas como poder. Os conselhos de Platão nos indicam que a gênese da teoria do rei-filósofo fundamenta-se numa ação contra a tirania. ${ }^{40}$

Essa ação, centrada na dikaiosyne, deve ser capaz de nos permitir a visão da reta politéia, tanto na cidade quanto no indivíduo. Mas, como determinar essa ação se não há lugar para ela na cidade? Se Atenas condena Sócrates, como permanecer fiel à philosophía, numa cidade que não lhe reserva senão a pecha de "inútil" e "perversa"? ${ }^{41}$

Se Sócrates levou a ação de filosofar ${ }^{42}$ às últimas conseqüências, escolhendo a cicuta, Platão, enquanto seu herdeiro, também levou as palavras finais do mestre, em sua defesa frente ao tribunal, às últimas conseqüências. Como tornar visível o melhor caminho - o de Sócrates que caminha para a morte ou o de seus juízes que caminham para a vida - ao olhar dos homens? ${ }^{43}$ De certo modo, o F'édon já contém a escolha do melhor caminho. Quando Sócrates diz que filosofar consiste em aprender a morrer, ${ }^{44}$ a ação que emerge dessa aprendizagem é aquela que se conforma na escolha e no caminho de Sócrates: o de não temer a morte. ${ }^{45}$ Como decifrar o enigma contido nas derradeiras palavras de Sócrates a seus juízes? Sócrates, se seguirmos as informações do F'édon, deixa, em sua última conversa com os discípulos, a pista para a decifração do enigma: o reto uso da palavra. ${ }^{46}$

${ }^{40}$ Carta VII, 327 a: «Em minhas relações com Díon, que era jovem ainda, expondo-lhe minhas idéias sobre o que me parecia melhor para os homens e estimulando-o a realizá-las, é muito provável que eu não me desse conta que de alguma maneira trabalhava, sem o saber, para a queda da tirania». (O grifo é nosso.)

43 Apologia 42 a: «Mas é chegada a hora de partirmos, eu para a morte, vós para avida. Quem segue melhor rumo, se eu, se vós, é invisível para todos; menos para a divindade».

44 Fédon, $64 \mathrm{a}-\mathrm{b}$.

45 Apologia, $40 \mathrm{c}-42$ a.

${ }_{F}^{46}$ édon, 115 e: «Eû gàr isthi ê d’hós, ô áriste Kríton, tò mè kalôs légel ou mónon eis autò toûto plemmelés, allà kaì kakón ti empoieî taîs psykhaîs». 
$\overline{\mathrm{E}}$ pois nessa senda que Platão articula seu pensamento: partindo da tarefa deixada por Sócrates, mas reinventando a prática socrática do diálogo na palavra escrita. ${ }^{47}$ Esta, como lugar da imprecisão em relação àquilo que é pensado, tal como o corpo é uma prisão para a alma, deve por isto mesmo assumir um sentido histórico ao resistir ao movimento da História. ${ }^{48}$ Ao antigo sábio bastava a palavra do deus, ao filósofo é necessário não só a palavra, mas o diálogo, para que através dele a sophía possa emergir. ${ }^{49}$ No diálogo, a palavra escrita deixa de ser passiva, embora seja sempre insuficiente para dizer a verdade, passando a ter uma força de resistência. Se a História se manifesta como movimento, a escrita deve constituir-se como ação de resistência à esta mundaneidade. E aí a dikaiosyne emerge como a regra $d a$ vida ${ }^{50}$ - tanto do indivíduo, quanto da cidade - que legitima a ação do filósofo.

Ora, se na cidade histórica não há lugar para o homem "sábio e justo" que foi Sócrates, é preciso inventar uma cidade onde a filosofia seja seu fundamento. Inventá-la não com as armas da

47

Ver a análise de J. Svenbro (1988) que, ao estabelecer a analogia entre a escrita e o ator, abre uma nova possibilidade para a compreensão do tema da escritura em Platão: «L'espace écrit est une 'scène' qui emprunte sa logique au spectacle théâtral, en attribuant le rôle du spectateur au lecteur. Il intériorise le théâtre. (...) Dans la carrière de Platon, le passage soudain du genre tragique aux dialoques peut effectivement se comprendre comme une intériorisation du théâtre dans le livre, car les dialogues ont une forme thêâtrale, sans pour autant être destinés au théâtre. Si la politeía de Platon a une destination scènique, sa 'scène' est celle de la cité entiére, opposée à cele, trompeuse, du théâtre ordinaire. Aisin, pour toute son hostilité au thêâtre, sa pensée utopique serait essentiellement théâtrale». (p. 198-9). Sobre esta questão ver também Findlay (1974), Havelock (1968).

48

Nas Leis, ao descrever o nascimento das cidades, Platão nos mostra que a escrita nasce a partir do momento em que as diferentes politeiai se conformam. Cf. Leis III, $677 \mathrm{c}-\mathrm{d} ; 680 \mathrm{a}-\mathrm{e} ; 702 \mathrm{a}$.

49

O verdadeiro diálogo consiste não na erística dos sofistas, mas num movimento onde faremos «chocar, uns com os outros, nomes, definições, percepções da vista e impressões dos sentidos, quando se discutir em discussões benévolas, em que a inveja não dite nem as perguntas nem as respostas». Carta VII $334 \mathrm{~b}$.

50

Rep. I, $352 \mathrm{~d}$.

CLASSICA, Belo Horizonte, $3: 45-66,1990$ 
política dos diferentes estados históricos, mas com as armas da philosophía, fazendo do "ato-escrita" de inventar cidades a ação possível do filósofo em meio ao movimento da História. E aqui podemos inferir uma grave consequiência da reflexão platônica acerca da morte de Sócrates: a construção da cidade justa como uma armadilha, como um tópos onde é o próprio pensar que se põe em questão.

Das aventuras de Platão em Siracusa não devemos, portanto, inferir um "ideal impossível e utopizante" — que fez escola a partir da crítica de Aristóteles à República - mas, ao contrário, a exigência trágica da conformação do lugar do philósophos como um tópos, onde o lógos e a pólis são essenciais.

Tanto o discurso de Sócrates sobre a cidade justa, quanto o de Trasímaco e seus herdeiros, Gláucon e Adimanto, acerca da cidade injusta, exigem a mediação da pólis pois a cidade e o homem absolutamente injustos e a cidade sã e o homem absolutamente saudável da primeira cidade descrita por Sócrates são incapazes de agir

... uma vez que os que são completamente maus inteiramente injustos são também inteiramente incapazes de agir. ${ }^{51}$

Se a injustiça "produz as revoltas, o ódio, as contendas",52 ela termina por dissolver a cidade;"53 se a justiça "gera a concórdia e a amizade", é ela que permite a emergência da cidade.

Assim, a justa cidade "utópica" só adquire sentido na medida em que se configura como a regra de vida que preenche os significados do caminho do philósophos até sua morte e legitima sua ação no seio das contendas da pólis, uma vez que a ação justa só se torna visível a partir do contraponto da ação injusta.

\footnotetext{
51

Rep. I, $353 \mathrm{c}-\mathrm{d}$.

62

Rep. I, 351 d: «Stáseis gàr pou, ô Thrasymakhe, hé ge adikía kaì míse kaì mákhas en alléllois parékhei, he dè dikaiosyne homónoian kaì philían». 63

Sobre a dissolução das cidades, mesmo da cidade justa, ver República VIII, 546 a, e o livro $\Pi 1$ das Leis.
} 
Ao construir a cidade justa da República, acreditamos que Platão está empenhado em mostrar que o conflito entre o philósophos e a pólis é insuperável. Todo o contexto do diálogo remete para este conflito, que determina a ação do philósophos: a casa de Céfalo, no Pireu, é por si só o espaço metafórico deste conflito. Já Proclo, em seu comentário à Repriblica, ${ }^{54}$ observava que a escolha do Pireu e a proximidade com o mar - que, segundo o texto das Leis, torna as cidades um tanto salobres e faz com que a vida cotidiana seja invadida pelo comércio, gerando nos homens costumes instáveis, cheios de malícias e por fim, sujeitando-os à maior calamidade para uma cidade que almeja a justiça e a nobreza, que é o mercantilismo do ouro e da prata ${ }^{55}$ - essa escolha nos remete ao lugar das disputas e das discórdias, refletindo os "combates sofísticos" em que a discussão sobre a dikaiosyne e a politeía se dá. ${ }^{56}$

Por outro lado, o Pireu, urbanizado por Hipodamos de Mileto, é também a metáfora da "ação de inventar cidades" e o espaço de manifestação daquelas "naturezas" que, apesar do fluxo mundano da História, permanecem fiéis à philosophia. ${ }^{57}$ nele que se encontram cidadãos e estrangeiros; é nele que a philia, a hospitalidade em relação àquilo que é xénos, se manifesta.

54

Proclus, Commentaire sur La République, 1ère dissertation, 16.26 - 18.7: «Quant au lieu, (...) qu'avait été le Pirée (...), que les lieux au bord de la mer sont necessairement remplis de la vie tumultueuse et bigarrée, tandis que les villes plus éloignées de la mer sont libres de ces maux».

65

Veja-se o livro IV das Leis, 704 a-705 b.

56

Proclus. Commentaire sur La République, I, 17, 15-25. 57

$\mathrm{Na}$ Repriblica VI, $495 \mathrm{c}$, Sócrates reconhecerá que mesmo as naturezas filosóficas podem «decair» de sua ocupação natural deixando a philosophía «solitária e incompleta, vivendo uma vida que não lhe convém nem é verdadeira, cobrindo-a de vergonha e insultos». Ao enumerar as poucas naturezas que não se deixaram corromper - aquelas que, tendo sido bem educadas, foram afastadas de sua cidade pelo exílio, permanecendo, assim, fiéis à filosofia; aquelas que, afastando-se com razão de outra arte que desprezam, vêm para a Filosofia, para a qual são naturalmente dotadas; e aquelas que, como Sócrates, são impedidas pelo seu daimónion de a abandonar - e permanecem dignas de conviverem com a philosophía, Sócrates já nos indica o tópos dos filósofos na cidade. 
A descida de Sócrates ao Pireu (katében khtès eis Peiraiâ) é já um prenúncio da descida do philósophos à caverna; e a construção da cidade justa, o modo de ação de volta à caverna. ${ }^{58}$

Enquanto "desenhador de politéia" (politeiôn zográphos) e "demiurgo" da reta ordem, 59 a ação do philósophos deve ser semelhante àquela de Hefestos e Atena.

Como Hefestos, que com metais preciosos modelava "andróides", ele modelará com palavras os homens que habitarão a cidade justa, tornando visíveis as "ligaduras" entre o mundo sensível e o mundo das idéias. Como Atena, ele deverá possuir a epistéme, que não só permite a condução da "nau do Estado", mas que também o torna apto a refletir sobre o percurso e o bom uso (o kairós) que se deve fazer dos incidentes que possam advir, de modo a não haver um desvio da rota originária.

$\mathrm{Na}$ realidade, o justo - homem ou cidade - é aquele que, possuindo a sabedoria, a coragem e a temperança, reconhece a justiça como princípio inerente à própria physis, incapaz, portanto, de ser sub-vertido pela História.

O "discurso utópico" nasce, pois, desta articulação entre o ver e o dizer que se manifesta pela escrita. Nesse sentido, a "escrita utópica" é a ação política possível ao filósofo em meio à corrupção da política pensada apenas como poder; ela não é um mero exercício de ludicidade filosófica, mas uma aprendizagem em que não

58

Desde a Antigüidade, conta-se que Platão teria reescrito muitas vezes a abertura da República (Diógenes Laércio, Vidas e Doutrinas... III, 37). Voegelin, (1957), em seu estudo sobre Platão e Aristóteles, salienta que o uso de katében na abertura do texto nos remete já a «the vista into the symbolism of depth and descent» (p. 52) e, identificando o Pireu com o Hades, vê, na descida de Sócrates, o prelúdio da descida de $\mathrm{Er}$ ao Hades, no mito com que Platão fecha a República. Sobre a abertura da República, veja-se ainda Sesonske (1961), Tucker (1900:20), Harrison (1967). E interessante observar airda que o verbo katabaino é usado por Homero para referir-se à descida de Odisseu ao Hades:

Ho gár moi psykhè manteúsato Teiresiao émati tôi, hóte dè katében dómon Háidos éso, nóston hetaíroisin dizémenos ed'emoì autôi.

( «Assim me anunciou a alma de Tirésia, no dia em que baixei à morada de Hades, a interrogá-la sobre o regresso dos companheiros e do meu. Odisséia XXIII, 221-3).

59

Rep. VI, $501 \mathrm{c.}$

CLASSICA, Belo Horizonte, $3: 45 \cdot 66,1990$ 
só o filósofo aprende, mas também deixa entrever o princípio que garante o próprio lógos.

Assim, a utopia na República não significa uma forma "alienante" de afastamento do filósofo da vida política, mas o re-verso, - espelho, da contemplação que o philósophos obtém ao sair da caverna, quando

... no limite do cognoscível é que se avista, a custo, a idéia do Bem; e uma vez avistada, compreende-se que ela é para todos a causa de quanto há de reto e belo; que no mundo visível, foi ela que criou a luz, da qual é senhora; e que, no mundo inteligivel, é ela senhora da verdade e da inteligência, e que é preciso vê-la para se ser sensato na vida particular e pública. ${ }^{60}$

Aquele que sai da caverna deve necessariamente retornar a ela, ... deve, portanto, cada um por sua vez, descer à habitação comum dos outros e habituar-se a observar as trevas. Com efeito, uma vez habituados, sereis mil vezes melhores do que os que lá estão e reconhecereis cada imagem, o que ela é e o que representa, devido a ter contemplado a verdade relativa ao belo, ao justo e ao bom. E assim teremos uma cidade para nós e para vós, que é uma realidade, e não um sonho, como atualmente sucede na maioria delas, onde combatem por sombras uns com os outros e disputam o poder, como se fosse um grande bem. ${ }^{61}$

Ao voltar à caverna, a "ascese-descedente" do filósofo constitui-se numa ação política que, não se sujeitando ao puro acontecer da História, garante a apreensão de seu sentido através de um imaginário que, se dá na História, mas que se fundamenta num princípio - a idéia de Bem - que a ultrapassa.

O filósofo, fiel à sua physis, deve sempre voltar a Siracusa e, mesmo que possa prever o fracasso de sua aventura, a ele não é dado escolher entre o lógos e a dóxa, como é possivel ao philódoxos. A sua moíra é ser fiel à sua escrita e esta, enquanto manifestação da verdade, deve ser vivida tal como Êdipo viveu o seu oráculo.

\footnotetext{
60

Rep. VII, 517 b-c (Tradução da Prof Maria Helena da Rocha Pereira, com modificações ) .

61
}

Rep. VII, 520 c-d. (Tradução da Prof* Maria Helena da Rocha Pereira). 


\section{BIBLIOGRAFIA}

\section{Textos Antigos}

ARISTOPHANE, Les oiseaux. Traduction de V. Coulon et $\mathrm{H}$ Van Daele. Paris, Les Belles Lettres, 1980. t. 3.

ARISTOTE, The Politics of Aristotle. With an introduction, two prefatory and notes critical and explanatory by W.L. Newman. Oxford, Oxford University Press, $19534 \mathrm{v}$.

. Politique. Introduction. Livres I-II. Traduction de Jean Aubonnet. Paris, Les Belles Lettres, 1957. t. 1. 1963 t. 1-2.

DIOGENES LAERTIUS, Lives of Eminent Philosophers. With an English Translation by R. D. Hicks. Cambridge, Massachusetts, Harvard University Press, 1979. 2 v. (Loeb Classical Library).

HESfODO. Les Travaux et les Jours. Texte traduit et établi par Paul Mazon. Paris, Les Belles Lettres, 1951.

\section{R. Kempf, 1981.}

HIPOCRATES. Oeuvres Complètes d'Hippocrate. Introduction, traduction et notes par Emile Littré. Amesterdam, Adolf Hakker Editions, 1961. (reimpressão da edição francesa de 1839). v. 4.

HOMERO. L'Iliade. Texte établi et traduit par Paul Mazon. Paris, Les Belles Lettres, 1959. $4 \mathrm{v}$.

e M. Alves Correia. Lisboa, Livraria Sá da Costa Editora, 1939. 2 v.

PROCLUS. Commentaire sur La République. Traduction et notes par J. Festugière. Paris, J. Vrin, CNRS, 1966. v. 1.

\section{Estudos E ComentáRIos}

ARENDT, Hannah. A condição humana. 'Tradução de Roberto Raposo. Rio de Janeiro, Forense, 1983.

ARENDT, Hannah. Homens em tempos sombrios. Tradução de Denise Bottmann. São Paulo, Companhia das Letras, 1987.

BAILLY, A. Distionnaire Grec-Français. Edition revue par Léon Séchan e Pierre Chantraine. Paris, Hachette, 1984.

BARKER, Ernest. Greek Political Theory. London, Methuen, 1977. (reimp.)

BLUCK, R. S. Plato's Seventh and Eight Letters. Cambridge, Cambridge University Press, 1947.

BOISACQ, Emile. Dictionnaire Étymologique de la Langue grecque. 4. ed. Heidelberg, Carl Winter, 1950.

CHANTRAINE, Pierre. Dictionnaire Etymologique de la Langue Grecque. Paris, Klincksieck, 1968. 2. v.

CORNFORD, F. M. Plato's Cosmology. London, Routledge \& Kegan Paul, 1952.

DAVIS, J. C. Utopia and the Ideal Society. Cambridge. Cambridge University Press, 1981. 
DODDS, E. R. The Ancient Concept of Progress and other Essays on Greek Literature and Belief. Oxford, Oxford University Press, 1973.

DOXIADIS, C. A. Entre Dystopia y Utopia. Madrid, Ed. Moneda y Credito, 1969.

EDELSTEIN, L. Plato's Seventh Letter. Leiden, E. J. Brill, 1966.

FINDLAY, J. N. Plato. The written and unwritten doctrines. London, Routledge and Kegan Paul, 1974.

FRITZ, Kurt von. The relevance of Ancient Social and Political Philosophy for our Times. Berlin, New York, Walter de Gruyter, 1974.

FERGUSON, John. Utopias of the Classical World. London, Thames and Hudson, 1975.

GOLDSCHMIDT, V. Platonisme et Pensée Contemporaine. Paris, Aubier, 1970.

GRENE, D. Greek Political Theory, the images of man in Thucydides and Plato. Chicago, London Phoenix, Chicago University Press, 1967.

GULLEX, N. The authenticity of the platonic epistles. In: Entretiens sur L'Antiquité Classique. Pseudegrapha I. Vandoeuvres, Fondation Hardt, 1972. p. 103-130.

HARRISON, E. L. Plato's Manipulation of 'Thrasymachus. Phoenix. 21(1): 27-39, 1967.

HANSOT, Elisabeth, Perfection and Progress: two modes of utopian thought. Cambridge, Massachussets, The MIT Press, 1974.

HAVELOCK, Eric. The orality of Socrates and the literacy of Plato. In: KELLY, Eugene, ed. New Essays on Socrates. Washington, University Press of America, 1984:67-93.

The evidence for the theaching of Socrates. In: PATZER, Andreas. Der Historische Sokrates. Darmstadt, Wissenschaftliche Buchgessellschaft, $1987: 240-53$.

. The Liberal Temper in Greek Politics, London, New Haven, Yasle University Press, Jonathan Cape, 1952.

University Press, 1978.

- The muses learn to write. New Have, London, Yale University Press, 1986.

HAWARD, J. The Seventh and Eighth Platonic Epistles. Classical Quarterly. $22(3-4): 143-54,1929$.

JOLY, Henri. Le renversement platonicien. 2. éd. corrigée. Paris, J. Vrin, 1986.

LESKY, A. História de la Literatura Griega. Versión Española de José María Diaz y Beatriz Romero. Madrid, Editorial Gredos, 1988.

LEVEQUE, Pierre \& VIDAL: NAQUET, Pierre. Clisthène L'Athènien. Paris, Besançon, Annalles Littéraires de L’Université de Besançon, Les Belles Lettres, 1964.

LIDDELL, H. J. \& SCOTT, R. A Greek English Lexicon. Oxford, Oxford University Press, 1983.

MAMUEL, Frank E. \& MANUEL, Fritzie P. Utopian Thought in the Western World. Cambridge, Massachussets,. The Belknap of Havard University Press, 1979. 
NESTLE, Wilhelm. Storia della religiosità greca. Traduzione di A.B. (Aggiornamento bibliografico di Giulia Piccaluga). Firenze, La Nuova Italia, 1973.

NISBET, R. History of the idea of progress. New York, Basic Books, 1980.

PASQUALI, Giorgio. Le Lettere di Platone. Firenze, Felice le Mounier, 1938.

POPPER, K. A sociedade aberta e sens inimigos. Tradução de Milton Amado. Belo Horizonte, Itatiaia, 1959.

REVERDIN, Olivier. Ed. Hésiode et son influence. Entretiens sur l'Antiquité Classique. Vandoeuvres, Fondation Hardt, 1970.

RUYER, Raymond. L'utopie et les utopies. Paris, PUF, 1950.

SESONKE, A. Plato's Apology: Republic I. Phronesis. 6(1): 29-38, 1961.

SINCLAIR, T.A. History of Greek Political Thought. London, Routledge \& Kegan Paul, 1967.

SOLMSEN, F. Hesiodic motifs in Plato. In: Reverdin, O. ed. Hésiode et son influence. Entretiens sur l'Antiquité Classique. Vandoeuvres, Fondation Hardt, 1970 .

STRAUSS, L. The city and man. Chicago, London. The University of Chicago Press, 1978.

. De la Tyrannie. Hièron ou le Traité sur la Tyrannie. Traduit par H. Kern. Paris, Gallimard, 1983.

- Droit Naturel et Histoire. Traduit par M. Nathan et E. de Dampierre. Paris, Flammarion, 1986.

SVENBRO, Jasper. Pharasiłleia. Anthropologie de la lecture en Grèce Ancienne. Paris, Editions La Découverte, 1988.

TROUSSON, Raymond. Voyage aux Pays de Nulle Part. Bruxelles, Editions de l'Université de Bruxelles, 1979.

TUCKER, T. G. The Proem to the ideal commonwealth of Plato. London, Bell, 1900 .

VERDENIUS, W. J. Aufbau und Abschit der Erga. In: Reverdin, O. ed. Hésiode et son influence. Entretiens sur l'Antiquité Classique. Vandoeuvres, Fondation Hardt, 1960.

VERNANT, Jean-Pierre. Mito e Pensamento entre os gregos. Tradução de Haiganuch Sarian, São Paulo, Difel, 1973.

VOEGELIN, Eric. Oder and History: Plato and Aristotle. Louisiana, Baton Rouge, Louisiana State University Press, 1957. v. 3.

WOLIN, Sheldon S. Politica y Perspectiva. Continuidad y cambio en el pensamiento politico occidental. Buenos Aires, Amorrortu Editores, 1974.

Este trabalho é parte de pesquisa mais abrangente acerca das relações entre a política e a utopia no pensamento de Platão, parcialmente financiada pela Capes e CNPq, a quem agradecemos. 